\title{
EVALUACIÓN DEL DESEMPEÑO DE UN LECHO FLUIDIZADO DE TIPO SURTIDOR (LFTS) PROVISTO DE GUIADORES CILINDRICOS NO POROSOS EN LA DESAPONIFICACIÓN DE GRANOS DE QUINUA
}

\author{
Mirea Flores, Ramiro Escalera y Carla Quiroga
}

\section{RESUMEN}

Este trabajo de investigación evalúa el uso de guiadores en un lecho fluidizado de tipo surtidor (LFTS) en el proceso de remoción de saponinas de quinua real (ecotipo amarilla). Se utilizaron guiadores cilíndricos no porosos con superficies abiertas laterales de $30 \mathrm{~mm}$ y $50 \mathrm{~mm}$ de altura medida desde la parte inferior. Se utilizó 2 reactores de vidrio cilíndrico cónico de 7,44 y $14,34 \mathrm{~cm}$ de diámetro y conos de $30^{\circ}$ y $45^{\circ}$ respectivamente, con boquillas que varían de 1,5 a $5 \mathrm{~mm}$ de diámetro de orificio, conectadas a un flujómetro digital alimentado de aire por un compresor de $4001 \mathrm{~min}^{-1}$ de capacidad. En pruebas de caracterización del lecho con y sin guiadores se evaluó las relaciones entre la velocidad lineal de aire en la entrada al surtidor, la presión manométrica, el flujo volumétrico de aire, tiempo de ciclo de la partícula y la velocidad másica de circulación de sólidos dentro del LFTS. Posteriormente, se elaboró un diseño experimental factorial de 4 factores a 2 niveles $\left(2^{4}\right)$ por duplicado, generando 32 corridas en las que se evaluó el efecto del diámetro de lecho, el diámetro de boquilla, la altura de lecho y la altura de la zona de entrada de granos al guiador en la pérdida de masa, concentración residual de saponinas en el grano y el consumo específico de energía. La mayor eficacia de remoción de saponinas corresponde a las condiciones de operación del LFTS con menor diámetro de boquilla $\left(\varnothing_{\mathrm{b}}=2 \mathrm{~mm}\right)$, mayor altura de zona de entrada de granos $\left(\mathrm{H}_{\mathrm{D}}=50 \mathrm{~mm}\right)$, mayor diámetro de lecho $(14,4 \mathrm{~cm})$ y menor altura de lecho $\left(\mathrm{H}_{\mathrm{L}}=21,5 \mathrm{~cm}\right)$. En estas condiciones geométricas, a los 81 minutos de procesamiento, se logró una concentración residual de saponinas del 0,032 \% y una eficiencia de remoción de saponinas del 52,64\%. A mayores velocidades lineales en la entrada al surtidor y mayores frecuencias de ciclo del grano se obtiene mejores eficiencias de remoción de saponinas y menores concentraciones residuales de saponinas en el grano. En general, se puede concluir que para obtener concentraciones residuales mínimas de saponinas en los granos y eficiencias de remoción superiores al 90\%, será apropiada cualquier configuración que genere velocidades lineales en la entrada al surtidor entre 1000 y $1300 \mathrm{~ms}^{-1}$ y frecuencias del orden de 20 CPM. Menores velocidades de circulación de granos en un LFTS con guiador, respecto de las que se obtienen en lechos sin guiador, generan una falta de uniformidad en la concentración de saponinas en el grano tratado y menores eficiencias de remoción.

Pal abras Clave: Remoción de Saponinas de Quinua, Lecho Fluidizado de Tipo Surtidor con Guiadores, Flujo Másico de Circulación de Granos.

DOI: 10.23881/idupbo.019.1-3i 